\title{
Standardized Extracts from Hawthorn Leaves and Flowers in the Treatment of Cardiovascular Disorders - Preclinical and Clinical Studies
}

Authors

Affiliations
Egon Koch ${ }^{1}$, Fathi Abdul Malek ${ }^{2}$

${ }^{1}$ Preclinical Research, Dr. Willmar Schwabe GmbH \& Co. KG, Karlsruhe, Germany

${ }^{2}$ Clinical Research, Dr. Willmar Schwabe GmbH \& Co. KG, Karlsruhe, Germany
Key words

- Crataegus spp.

- Rosaceae

- cardiovascular diseases

- cardioprotection

- vasoprotection

- atherosclerosis

- nitric oxide

- restenosis

\section{Abstract}

$\nabla$

Extracts from different parts of hawthorn plants (Crataegus spp.) are used worldwide for the treatment of cardiovascular diseases. So far, almost all clinical studies have been conducted with standardized hydroalcoholic extracts from leaves and flowers. These trials with more than 4000 patients have provided evidence for clinical benefits in the therapy of mild chronic heart failure. Besides cardiotonic effects, recent pharmacological

\section{Introduction}

$\nabla$

The hawthorn plant, Crataegus spp. (Rosaceae), is used worldwide as an herbal remedy in the treatment of chronic heart failure (HF). Hawthorn preparations are available in various forms ranging from infusions and tinctures to standardized extracts and may be available variously as authorized prescription drugs, over-the-counter (OTC) medications, authorized herbal medicinal products, dietary supplements, or unregulated herbal remedies depending on the regional regulatory requirements. Extracts may be prepared using hydroalcoholic (methanol or ethanol) or waterbased extraction and are derived from various plant parts including, most commonly, berries or leaves and flowers. While many preparations are poorly characterized, the pharmacological properties of some standardized extracts have been thoroughly investigated in in vitro experiments, in animal studies, and in human clinical trials. To date, almost all clinical and most pharmacological investigations have been performed with aqueous alcoholic extracts from leaves and flowers such as LI 132 (70\% methanol extract) and WS ${ }^{\circledR} 1442$ (45\% ethanol extract) [1]. This article is intended to briefly summarize the current pharmacological and clinical data relating mainly to these two extracts. investigations indicate that hawthorn extracts also possess cardio- and vasoprotective properties. Thus, these extracts may also be employed in the prophylactic and therapeutic treatment of such conditions as endothelial dysfunction, atherosclerosis, coronary heart disease, or prevention of restenosis/reocclusion following peripheral endovascular treatment. In this review the pharmacological and clinical data relating to these standardized extracts are summarized.

\section{Plant Material and Extract Preparation}

Hawthorn species (Crataegus spp.; family Rosaceae) grow as shrubs or trees with thorny twigs throughout the temperate zones of the Northern hemisphere. According to the European Pharmacopoeia (EP), hawthorn leaves and flowers consist of the whole or cut, dried, flower-bearing branches of $C$. monogyna Jacq. (Lindm.), C. laevigata (Poir.) DC. (C. oxyacanthoides Thuill.) or other European Crataegus species, including C. pentagyna Waldst. et Kit ex Willd., C. nigra Waldst. et Kit, and $C$. azarolus $\mathrm{L}$. as well as their hybrids.

The source material contains a range of pharmacologically active substances, the most important being flavonoids ( $1.5 \%$ to $2 \%$, calculated as hyperoside equivalence according to $\mathrm{EP}$ ) such as vitexin, hyperoside, rutin, or vitexin-2"-O- $\alpha$-Lrhamnoside ( $\bullet$ Fig. $\mathbf{1}$ ), and catechin/epicatechin derived oligomeric procyanidins (OPC) ( $\bullet$ Fig. 2 ) with a varying degree of polymerization (1\% to $3 \%$, cyanidine chloride equivalence per EP). Further constituents are triterpenic acids (approximately $0.6 \%$ ), e.g., ursolic, oleanolic, and crataegolic acid, and phenol carboxylic acids such as chlorogenic and caffeic acid, as well as various amines [2-5].

Extracts are produced from the herbal material using either water or a hydroalcoholic solvent 


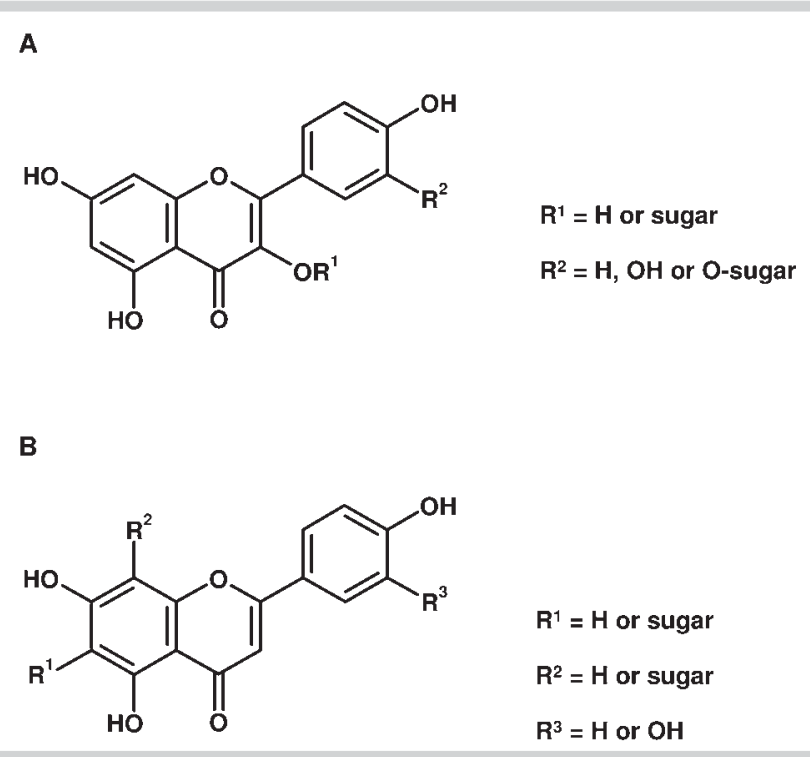

Fig. 1 In Crataegus leaves and flowers a series of flavonols (A) and flavones (B) have been identified. The flavone series is mainly based on apigenin and luteolin whereas quercetin, kaempferol, and 8-methoxykaempferol represent the basic structures of the flavonol series. These flavonoids almost exclusively occur as glycosides. As sugar residues, $\beta$-D-glucose, $\alpha$-L-rhamnose, $\alpha$-L-4-acetyl-rhamnose, xylose, arabinose, rutinose, and neohesperidose have been observed. Apigenin and luteolin have been found to form $\mathrm{C}$ - and O-glycosides while for flavonols only O-glycosides have been described [5].

equivalent in strength to a minimum of $45 \%$ ethanol. Aqueous extracts contain a minimum of $2.5 \%$ flavonoids and dried hydroalcoholic extracts a minimum of $6.0 \%$ flavonoids expressed as hyperoside. WS ${ }^{\circledR} 1442$ is a standardized dry extract (extraction solvent $45 \%$ ethanol) adjusted to a content of $18.75 \%$ OPC with a starting plant material/extract ratio of 4 to $7: 1$ (manufacturer: Dr. Willmar Schwabe GmbH \& Co. KG) while LI 132 (extraction solvent $70 \%$ methanol) is adapted to a content of $2.2 \%$ flavonoids (manufacturer: MCM Klosterfrau Vertriebsgesellschaft mbH) [3, 4].

\section{Pharmacology \\ $\nabla$}

\section{Myocardium}

Using isolated rat cardiomyocytes, LI 132 exhibited a positive inotropic effect on the contraction amplitude similar to the betaadrenergic agonist isoprenaline and the cardiac glycoside ouabain. However, in contrast to these positive inotropic interventions, the effects of the hawthorn extract were significantly more economical with respect to the energetics of the myocytes [6]. A positive inotropic effect was also seen in electrically stimulated canine papillary muscles [7]. It has been suggested that this effect is due to an enhanced intracellular $\mathrm{Ca}^{2+}$ sensitivity [6]. In normal human myocardial tissue, WS ${ }^{\circledR} 1442$ has been shown to increase the contractile force, to raise the cell membrane calcium gradient and to displace ${ }^{3} \mathrm{H}$-ouabain on cell membranes. As the extract did not influence the activity of adenylyl cyclase, the pharmacological mechanism is suggested to be comparable to the cAMP-independent positive inotropic action of cardiac glycosides which is mediated via inhibition of the sodium pump $\left(\mathrm{Na}^{+} / \mathrm{K}^{+}\right.$-ATPase). Interestingly, low molecular weight fractions of this extract also

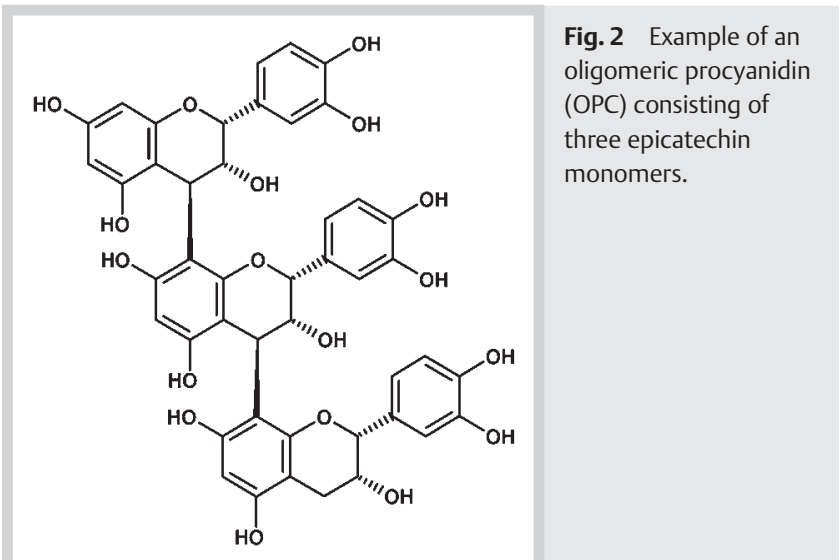

displaced ${ }^{3} \mathrm{H}$-ouabain, but did not show a calcium elevating response [8]. This could indicate different sodium pump binding constituents, or may reflect alternative signaling mechanisms associated with the $\mathrm{Na}^{+} / \mathrm{K}^{+}$-ATPase. It is now well established that this membrane protein, in addition to classical ion transporting, also mediates extracellular ouabain-binding signaling into the cell through regulation of protein tyrosine phosphorylation. The downstream signals following ouabain-triggered protein phosphorylation events include the activation of mitogen-activated protein kinase (MAPK) signal cascades, mitochondrial reactive oxygen species (ROS) production, as well as activation of phospholipase C (PLC) and the inositol trisphosphate (IP3) receptor [9-11]. In a further study, a significant concentration-dependent effect of WS ${ }^{\circledR} 1442$ on the contraction of electrically stimulated myocytes isolated from right atria and left ventricles of failing human hearts has been reported [12].

In an attempt to get information on the mechanism responsible for the positive inotropic action of LI 132, no influence on the Ltype calcium current was detected. Thus, an inhibition of phosphodiesterases or a beta-sympathomimetic action, which had previously been proposed to account for the cardiotonic action of hawthorn extracts, may be excluded as both of these activities would be associated with an increase in the L-type calcium current [13].

In rat cardiomyocytes [6] and in isolated guinea pig hearts [14], a prolongation of the refractory period was observed in the presence of hawthorn extracts providing evidence for an antiarrhythmic potential. Generally, an unusual profile has been obtained since in addition to exerting negative chronotropic effects (without $\beta$-adrenoceptor antagonism), the extracts act antiarrhythmically, and can induce rhythmicity in quiescent cardiomyocytes [15]. Fractionation of extracts by molecular size shows that these activities are present in different fractions and therefore are attributable to multiple substances. These authors also observed a decreased contraction frequency of neonatal murine cardiomyocytes in the presence of hawthorn extracts. As this effect was blocked by atropine and himbacine it appears to be mediated via muscarinic M2 receptor activation [16].

In guinea pig papillary muscles, LI 132 significantly increased action potential duration and time required for recovery of the maximum upstroke velocity, indicating class III and class I antiarrhythmic effects, respectively. Prolongation of the action potential duration may be due to a weak blockade of both delayed and inward rectifier potassium currents [13]. 
Ischemic reperfusion injury is associated with a substantial release of reactive oxygen species following reoxygenation of the ischemic tissue. This is linked with extensive localized cellular destruction, inflammatory reactions, activation of redox signaling, and induction of apoptosis, which in turn releases further free radicals and prolongs this circulus vitiosus. Reperfusion can also cause a loss of $\mathrm{Ca}^{2+}$ control and an uncontrolled influx of $\mathrm{Ca}^{2+}$, leading to the development of cardiac arrhythmias.

Both LI 132 and WS ${ }^{\circledR} 1442$ have been shown to be cardioprotective against ischemic reperfusion injury. In rats fed a diet containing 2\% LI 132 for 3 months, tissue damage following left coronary artery occlusion and subsequent reperfusion was determined by lactate dehydrogenase (LDH) release. LDH release was reduced by $>50 \%$ in treated vs. control animals $(1777 \pm 452 \mathrm{mU} / \mathrm{min}$ vs. $3795 \pm 512 \mathrm{mU} / \mathrm{min}$ ) [17]. Oral therapy of rats with $\mathrm{WS}^{\circledR} 1442$ for 7 days effectively reduced reperfusion induced arrhythmias, mortality, and hypotensive crises resulting from occlusion of the left coronary artery, but the increase of creatine kinase remained unaffected [18]. In a similar study, cardiac ischemia in rats was extended over 240 minutes with a 15 -minute reperfusion period. The extent of ST segment elevation in the electrocardiogram (ECG), the incidence of ventricular arrhythmias, the size of the infarction zone, and mortality were significantly reduced in animals pretreated with WS ${ }^{\circledR} 1442$ [19].

The cardioprotective activity of WS ${ }^{\circledR} 1442$ appears to be mainly associated with the OPC fraction, which exhibits both strong antioxidative properties and inhibits neutrophil elastase [20]. Since restoration of blood flow into previously ischemic tissue is associated with the formation of oxygen free radicals and the accumulation as well as activation of leukocytes, it is suggested that these effects in combination with the improvement of endothelial functions (see below) present reasonable explanations for the cardioprotective properties of WS ${ }^{\circledR} 1442$.

In a recent publication, it has been suggested that the reduced apoptotic incidence seen after treatment of rats in an experimental ischemia-reperfusion model with a $C$. oxycantha extract is mediated by the regulation of signaling pathways comprising the serine-threonine kinase Akt and hypoxia-inducible factor 1 (HIF-1) [21].

Elevated blood pressure (BP) results in compensatory remodeling of the left ventricle (LV) wall. This is known as cardiac hypertrophy $(\mathrm{CH})$ and serves as an adaptive response in the short term, enabling the heart to cope with a greater load. Over longer periods, however, $\mathrm{CH}$ leads to irreversible changes in the left ventricular wall, which becomes harder, thinner, and weaker, resulting in a larger LV volume and ultimately leading to cardiac insufficiency. Calcineurin signaling is an important trigger of cardiomyocyte growth. In vitro, WS ${ }^{\circledR} 1442$ inhibits the phosphatase activity of calcineurin, suggesting that it may block growth signaling in vivo, and therefore could reduce $\mathrm{CH}$ in hypertension. Significantly elevated $\mathrm{BP}$ and $\mathrm{CH}$ can be induced in rats by aortic constriction (AC) or treatment with deoxycorticosterone (DOCA) and $\mathrm{NaCl} / \mathrm{KCl}$ supplementation of the drinking water. Treatment of these hypertensive rats with WS ${ }^{\circledR} 1442$ reduced the BP and inhibited the development of $\mathrm{CH}$ in a dose-dependent manner. Interestingly, BP remained unchanged (normal) in WS ${ }^{\circledR} 1442$-treated control rats without aortic constriction or DOCA-salt treatment [22]. Similarly, LV remodeling resulting from AC in Sprague-Dawley rats was significantly modified by WS ${ }^{\circledR} 1442$ treatment. The LV: body weight ratio increased by $34 \%$ within 4 weeks after surgery for both $\mathrm{WS}^{\circledR} 1442$-treated and untreated rats. However, the ventricular walls of WS ${ }^{\circledR} 1442$-treated rats were markedly thicker and the LV volumes significantly lower than those of the sham-treated controls [23]. This result was extended using an overload period of 5 months. Again, in both WS ${ }^{\circledR}$ 1442-treated and sham-treated animals, the LV: body weight ratio increased markedly ( $53 \%$ over non-AC controls). Just as with the shorter-term treatment, LV volume and size increased more in sham-treated animals ( $>20 \%)$ than in WS ${ }^{\circledR} 1442$-treated animals $(<10 \%)$. The reduction in contraction rate (i.e., weakening of cardiac muscle) was also lower in animals treated with higher doses of WS ${ }^{\circledR} 1442$ [24]. On a molecular level, AC increased the mRNA expression for atrial natriuretic factor (10-fold) and fibronectin (1.8-fold) in untreated animals. WS ${ }^{\circledR} 1442$ treatment diminished the enhanced gene expression by $80 \%$ and $50 \%$, respectively.

Circulating interleukin (IL)-1, IL-2, IL-6, or IL-10 levels were not altered in long-term studies designed to identify possible immunomodulatory mechanisms for the therapeutic effects of WS ${ }^{\circledR}$ 1442 against cardiac failure [25].

\section{Vascular endothelium}

Hawthorn extracts have repeatedly been reported to increase coronary flow $[14,26]$ apparently due to an enhanced release of the vasorelaxant nitric oxide (NO) from the vascular endothelium. In rat tissue, the vasodilating effect could be completely abrogated by N-nitro-L-arginine (L-NNA), a nitric oxide synthase (NOS) inhibitor, and the soluble guanylyl cyclase inhibitor ODQ. Indomethacine, a cyclooxygenase inhibitor, and aminoguanidine, a specific inhibitor of inducible NOS (iNOS), did not negate the hawthorn-induced vasodilation. This suggests that WS ${ }^{\circledR} 1442$ stimulation of NO release is mediated by endothelial NOS (eNOS) [27]. The endothelium-dependent vasorelaxant effect of $W^{\circledR}$ 1442 has further been demonstrated in the human mammary artery. In human tissue, WS ${ }^{\circledR} 1442$ activates eNOS via phosphorylation at serine 1177 . The NO mediated vasodilating mechanism appears to be largely associated with the OPC fraction [28]. Since the effects of the NO donor sodium nitroprusside was significantly augmented by $\mathrm{WS}^{\circledR} 1442$, even in the presence of L-NNA, the antioxidative effects of WS ${ }^{\circledR} 1442$ may also inhibit the metabolism of NO, thus increasing its potency [27]. Further studies with pig coronary artery rings indicate that eNOS activation may be secondary to the release of reactive oxygen species (ROS), which then serves to trigger the src/PI3/Akt signal cascades resulting in phosphorylation and thereby activation of eNOS [29]. These authors also obtained evidence that the endothelium-derived hyperpolarizing factor, besides release of NO, may contribute to the vasorelaxing activity of WS ${ }^{\circledR} 1442$.

Rat models suggest that hawthorn extracts may as well be helpful in preventing atherosclerosis and restenosis following angioplasty. Treating rats with WS ${ }^{\circledR} 1442$ from day 2 before to day 13 after angioplasty reduced neointima formation (vascular smooth muscle growth) and improved luminal volume compared with controls. Pathogenic neointima formation has been linked to platelet-derived growth factor (PDGF) $\beta$ in atherosclerosis and restenosis, which can be inhibited by polyphenols, a class of substances abundant in hawthorn extracts. In cell cultures, WS ${ }^{\circledR}$ 1442 inhibited PDGF receptor $\beta$ phosphorylation (activation) and reduced DNA synthesis in a concentration-dependent fashion [30]. Taken together, this indicates a clear therapeutic potential for WS ${ }^{\circledR} 1442$ in restenosis prevention.

Oxygen-derived free radicals and iNOS activation are also implicated in the pathology of endotoxin shock. In a rat model, WS ${ }^{\circledR}$ 1442 administered 1 hour prior to endotoxin injection provided 
protection against reduced cardiac output and an increase in peripheral resistance without affecting the heart rate or the mean arterial BP. These effects are likely to be related to the antioxidative properties of $\mathrm{WS}^{\circledR} 1442$ [31].

As heart failure is accompanied by inflammation leading to endothelial hyperpermeability and edema formation, possible effects of WS ${ }^{\circledR} 1442$ on endothelial barrier dysfunction were investigated. The extract effectively inhibited endothelial hyperpermeability, which was induced in vitro and in vivo by thrombin and histamine, respectively. A dual mode of action of WS ${ }^{\circledR} 1442$ was elucidated since it inhibited the barrier-destabilizing $\mathrm{Ca}^{++} / \mathrm{PKC} /$ RhoA pathway and activated the barrier-protecting cAMP/Rap1/ Rac1 signaling network [32].

\section{Lipid metabolism}

Hawthorn extracts may also have hypocholesterolemic properties by acting on blood cholesterol levels through a number of mechanisms. In rats fed an atherogenic diet for 6 weeks, reduced concentrations of total as well as low, very low, and high-density lipoprotein (LDL, VLDL, HDL) cholesterol were observed in the animals treated with a tincture prepared from hawthorn berries whose constituents are similar to the ones in leaves and flowers. The reduction in cholesterol was shown to be due to a combination of increased liver uptake, increased degradation, and decreased biosynthesis [33]. In later experiments, this treatment was also shown to inhibit the subsequent development of atherosclerosis [34]. Reductions in cholesterol and triglycerides following treatment with hawthorn berry extract have also been shown in hamsters fed high-cholesterol diets. The changes were accompanied by an increased expression of the liver enzyme cholesterol-7- $\alpha$-hydroxylase and lower levels of intestinal acylCoA: cholesterol acyltransferase (ACAT) [35]. An inhibition of ACAT activity by hawthorn extracts and some constituents such as the triterpenic acid components oleanolic acid and ursolic acid has also been observed in other hamster and cell culture experiments [36].

Treatment of human HepG2 cells (a perpetual human hepatocyte line) with WS ${ }^{\circledR} 1442$ induced a 5.6-fold upregulation of LDL-receptor (LDL-R) transcription. The activity was found to be mainly mediated by the OPC fraction. The extract also downregulated ApoB synthesis in a concentration-dependent manner. ApoB is a structural component of serum LDL particles, and also a competitive ligand of LDL-R, which is in turn responsible for binding serum LDL for elimination by receptor-mediated uptake [37].

\section{Pharmacokinetics}

$\nabla$

In mice, orally administered ${ }^{14} \mathrm{C}$-labelled OPCs and catechins were rapidly adsorbed, with measureable absorption of all labeled substances within 1 hour. Absorption rates ranged from 16\% to $40 \%$ depending upon the substance (overall $31 \%$ of total OPCs). Radioactivity was higher following repeated oral dosing [38]. The oral bioavailability of vitexin rhamnoside was assessed using a combination of chromatographic and mass spectroscopic techniques. Bioavailability was only $3.6 \%$ indicating either poor absorption or extensive first-pass metabolism [39]. A similar low oral bioavailability was observed for vitexin glucoside in a subsequent study by the same authors [40].

\section{Toxicity}

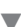

Following oral application of WS ${ }^{\circledR} 1442$, no signs of toxicity were observed for doses up to $3000 \mathrm{mg} / \mathrm{kg}$. The $\mathrm{LD}_{50}$ dose for intraperitoneal administration was measured for mice and rats as $1170 \mathrm{mg} / \mathrm{kg}$ and $750 \mathrm{mg} / \mathrm{kg}$, respectively (Schlegelmilch, personal oral communication, 1996). No clinical, chemical, hematological, morphological, or histological abnormalities could be identified in either dog or rats following 26 weeks of oral treatment at doses of $30 \mathrm{mg}, 90 \mathrm{mg}$, or $300 \mathrm{mg} / \mathrm{kg} /$ day. There was no evidence of genotoxicity of any kind including mutagenicity or clastogenicity. Teratogenicity was not apparent in rats or rabbits following oral dosing with up to $1600 \mathrm{mg} / \mathrm{kg}$ WS $^{\circledR} 1442$. In rats, neither peri- or post-natal development was influenced, nor was male or female fertility of treated animals or their F1 offspring [41]. Similarly, no adverse effect on fetal development was seen following daily gavage with $2.8 \mathrm{~g} / \mathrm{kg}$ of a leaf preparation at either days 1 to 8 or 8 to 15 of pregnancy [42]. Postmarketing surveillance as well as animal and clinical studies has shown no safety signals for carcinogenicity.

\section{Clinical Efficacy}

Hawthorn extracts are recommended in the treatment of chronic heart failure corresponding to a functional grading of New York Heart Association (NYHA) stage II (slight, mild limitation of activity; the patient is comfortable at rest or with mild exertion) $[3,4$, 43-45]. A considerable body of evidence, including a large number of clinical studies, largely with randomized, placebo-controlled, double-blind study designs, supports the clinical efficacy of hawthorn extracts, specifically of the standardized hydroalcoholic extracts LI 132 and WS ${ }^{\circledR} 1442$.

Statistically significant efficacy has been demonstrated in the treatment of heart failure in over 4000 patients. Treatment resulted in significant reductions in patients' subjective discomfort ratings, improved left-ventricular ejection fraction (LVEF) and cardiac efficiency (reduction in rate-pressure product). In addition, there was an increase in physical stress tolerance (elevation of anaerobic threshold), as well as improved cost/benefit performance. These conclusions are supported by smaller shortterm studies of placebo-controlled, double-blind [46-54], or open-label designs $[55,56]$, as well as by a large open-label study with over 700 patients [57].

The recently published SPICE trial was a large, randomized, placebo-controlled, double-blind study, involving a total of 2681 patients with NYHA II or III with LVEF $\leq 35 \%$ [58] despite a guideline-conform heart-failure-treatment. While $900 \mathrm{mg} \mathrm{WS}^{\circledR} 1442$ as an add-on therapy did not influence the time to the first cardiac event significantly, cardiac mortality was significantly reduced after 6 months $(\mathrm{p}=0.009)$ and 18 months $(\mathrm{p}=0.046)$. Furthermore, sudden cardiac death was significantly reduced for the subgroup of patients with $\mathrm{LVEF} \geq 25 \%$ ( $\mathrm{p}=0.025$ ). Tolerability (assessed as adverse events) was comparable in both groups.

In a randomized, double-blind, placebo-controlled study, 209 heart failure patients with more advanced stage of the disease (NYHA III) were treated with $1800 \mathrm{mg} \mathrm{WS}^{\circledR} 1442,900 \mathrm{mg} \mathrm{WS}^{\circledR}$ 1442 , or placebo, respectively, over 16 weeks [47]. For patients receiving $1800 \mathrm{mg} \mathrm{WS}{ }^{\circledR} 1442$, the maximal tolerated workload during a bicycle exercise test was significantly increased when compared to placebo. Typical heart failure symptoms as rated by the patients were significantly reduced in both WS ${ }^{\circledR} 1442$ groups 
in comparison to placebo. The same significant advantage of active therapy over placebo was observed when the changes in the score sums according to von Zerssen's list of complaints were tested for differences between the groups.

In the HERB CHF trial [46], the effect of $900 \mathrm{mg}$ daily WS ${ }^{\circledR} 1442$ ( $2 \times 450 \mathrm{mg}$ ) add-on therapy upon submaximal exercise capacity was compared with placebo in 120 NYHA II/III patients. The results revealed a statistically significant improvement in LVEF $(\mathrm{p}=0.04)$ under $\mathrm{WS}^{\circledR} 1442$ vs. placebo whereas the 6 -minute walk test was comparable in both groups.

In a randomized, placebo-controlled trial with 79 type-2 diabetes patients, adjunctive therapy with $1200 \mathrm{mg} /$ day LI 132 over 16 weeks significantly reduced the diastolic blood pressure, with no significant effect upon the systolic blood pressure [59].

According to the results of an open-label cohort study performed in 711 patients, the add-on treatment with WS ${ }^{\circledR} 1442$ led to significant improvements of quality of life in NYHA stage II coronary heart disease patients and demonstrated substantial and significant reductions in hospitalization costs due to heart failure [57]. The results of the individual clinical studies are further supported by a recent Cochrane review including 14 randomized, placebocontrolled, double-blind, clinical studies and describing the results of meta-analyses based on the 10 studies with data suitable for pooling. The results showed that hawthorn extracts are efficacious adjunctive treatments for CHF NYHA stage II [45]. The authors conclude that hawthorn extracts provided significant beneficial symptom control and physiological outcomes when used as adjunctive treatments for CHF.

\section{Adverse events and drug interactions \\ $\nabla$}

Adverse events (AEs) associated with the use of hawthorn extracts are rare and usually of mild to moderate severity. A comprehensive safety review of clinical study data for hawthorn extract treatments identified 29 clinical studies and examined data relating to AEs or drug-drug interactions from those 24 studies which met the inclusion criteria. The analysis included those 5577 of the 7311 patients for whom data were available. In the meta-analysis, hawthorn extract doses ranged from $160 \mathrm{mg}$ to $1800 \mathrm{mg}$ per day over a period of 3 to 24 weeks. The extracts used were generally either LI 132 or WS ${ }^{\circledR}$ 1442. In all, only 166 AEs were reported. Serious AEs have not been reported in association with WS ${ }^{\circledR} 1442$ and the incidence of AEs does not appear to be related to dose [60]. There are no case reports on drug interactions with hawthorn extracts [61], and in an interaction study with digoxin no effect on pharmacokinetic parameters by concurrent administration of $\mathrm{WS}^{\circledR} 1442$ was observed [62].

\section{Conclusions}

$\nabla$

Hawthorn extracts from leaves and flowers are widely used as an herbal remedy in the treatment of cardiac insufficiency. The extracts have been shown to contain a range of vaso- and cardioactive substances. Clinical studies in over 4000 patients confirm that standarized extracts such as WS ${ }^{\circledR} 1442$ are effective as an add-on therapy in the treatment of NYHA stage II and III chronic heart failure. In addition, these extracts possess further pharmacological effects which might be successfully applied in the prophylaxis and therapy of other cardiovascular disorders, e.g., endothelial dysfunction, atherosclerosis, coronary heart disease, or prevention of restenosis/reocclusion following peripheral endovascular treatment.

\section{Conflict of interest}

\section{$\nabla$}

Both authors are employees of Dr. Willmar Schwabe GmbH \& Co. $\mathrm{KG}$, the manufacturer of the standardized hawthorn extract $\mathrm{WS}^{\circledR}$ 1442.

\section{References}

1 Koch E, Busse WR, Juretzek W, Chevts V. Hawthorn. In: Encyclopedia of dietary supplements, 2nd edition. New York: Informa Healthcare; 2010: 411-422

2 European Pharmacopoeia 7.0, Vol.1. Strasbourg: Council of Europe; 2007: 1148-1151

3 Crataegi folium cum flore (hawthorn leaf and flower). In: ESCOP Monographs on the medicinal uses of plant drugs. Exeter: European Scientific Cooperative on Phytotherapy; 1999: 1-11

4 Folium cum flore crataegi. In: WHO Monographs on selected medicinal plants. Geneva: World Health Organization; 2002: 66-82

5 Kaul R. Der Weißdorn. Stuttgart: Wissenschaftliche Verlagsgesellschaft; 1998

6 Poepping S, Rose H, Ionescu I, Fischer Y, Kammermeier H. Effect of a hawthorn extract on contraction and energy turnover of isolated rat cardiomyocytes. Arzneimittelforschung 1995; 45: 1157-1161

7 Siegel G, Casper U, Schnalke F, Hetzer R. Molecular physiological effector mechanisms of hawthorn extract in cardiac papillary muscle and coronary vascular smooth muscle. Phytother Res 1996; 10: S195-S198

8 Schwinger RH, Pietsch M, Frank K, Brixius K. Crataegus special extract WS 1442 increases force of contraction in human myocardium cAMPindependently. J Cardiovasc Pharmacol 2000; 35: 700-707

9 Wang H, Haas M, Liang M, Cai T, Tian J, Li S, Xie Z. Ouabain assembles signaling cascades through the caveolar $\mathrm{Na}+/ \mathrm{K}+-$ ATPase. J Biol Chem 2004; 279: 17250-17259

10 Liu J, Tian J, Haas M, Shapiro JI, Askari A, Xie Z. Ouabain interaction with cardiac $\mathrm{Na}^{+} / \mathrm{K}^{+}$-ATPase initiates signal cascades independent of changes in intracellular $\mathrm{Na}+$ and $\mathrm{Ca} 2+$ concentrations. J Biol Chem 2000; 275: 27838-27844

11 Arnon A, Hamlyn JM, Blaustein MP. Ouabain augments $\mathrm{Ca}(2+)$ transients in arterial smooth muscle without raising cytosolic $\mathrm{Na}(+)$. Am J Physiol Heart Circ Physiol 2000; 279: H679-H691

12 Schmidt-Schweda S, von Burstin J, Möllmann H, Wollner S, Holubarsch C. Der positiv inotrope Effekt des Crataegus Spezialextrakt WS-1442 in isolierten Myozyten aus menschlichem Vorhof- und Ventrikelmyokard wird vorwiegend durch oligomere Procyanidine vermittelt. Z Kardiol 2000; 89 (Suppl. 5): 164

13 Müller A, Linke W, Klaus W. Crataegus extract blocks potassium currents in guinea pig ventricular cardiac myocytes. Planta Med 1999; 65: 335-339

14 Joseph G, Zhao Y, Klaus W. Pharmakologisches Wirkprofil von Crataegus-Extrakt im Vergleich zu Epinephrin, Amrinon, Milrinon und Digoxin am isoliert perfundierten Meerschweinchenherzen. Arzneimittelforschung 1995; 45: 1261-1265

15 Long SR, Carey RA, Crofoot KM, Proteau PJ, Filtz TM. Effect of hawthorn (Crataegus oxycantha) crude extract and chromatographic fractions on multiple activities in a cultured cardiomyocyte assay. Phytomedicine 2006; 13: 643-650

16 Salehi S, Long SR, Proteau PJ, Filtz TM. Hawthorn (Crataegus monogyna Jacq.) extract exhibits atropine-sensitive activity in a cultured cardiomyocyte assay. J Nat Med 2009; 63: 1-8

17 Al Makdessi S, Sweidan H, Mullner S, Jacob R. Myocardial protection by pretreatment with Crataegus oxyacantha: an assessment by means of the release of lactate dehydrogenase by the ischemic and reperfused Langendorff heart. Arzneimittelforschung 1996; 46: 25-27

18 Krzeminski T, Chatterjee SS. Ischemia and reperfusion induced arrhythmias: beneficial effects of an extract of Crataegus oxyacantha L. Pharm Pharmacol Lett 1993; 3: 45-48

19 Veveris M, Koch E, Chatterjee SS. Crataegus special extract WS 1442 improves cardiac function and reduces infarct size in a rat model of prolonged coronary ischemia and reperfusion. Life Sci 2004; 74: 19451955 
20 Chatterjee SS, Koch E, Jaggy H, Krzeminski T. In-vitro- und In-vivo-Untersuchungen zur kardioprotektiven Wirkung von oligomeren Procyanidinen in einem Crataegus-Extrakt aus Blättern mit Blüten. Arzneimittelforschung 1997; 47: 821-825

21 Jayachandran KS, Khan M, Selvendiran K, Devaraj SN, Kuppusamy P. Crataegus oxycantha extract attenuates apoptotic incidence in myocardial ischemia-reperfusion injury by regulating Akt and HIF-1 signaling pathways. J Cardiovasc Pharmacol 2010; 56: 526-531

22 Koch E, Spörl-Aich G. Oral treatment with the Crataegus special extract WS $^{\circledR} 1442$ inhibits cardiac hypertrophy in rats with DOCA-salt or aortic banding induced hypertension. Planta Med 2006; 72: 1061

23 Hwang HS, Bleske BE, Ghannam MM, Converso K, Russell MW, Hunter JC, Boluyt MO. Effects of hawthorn on cardiac remodeling and left ventricular dysfunction after 1 month of pressure overload-induced cardiac hypertrophy in rats. Cardiovasc Drugs Ther 2008; 22: 19-28

24 Hwang HS, Boluyt MO, Converso K, Russell MW, Bleske BE. Effects of hawthorn on the progression of heart failure in a rat model of aortic constriction. Pharmacotherapy 2009; 29: 639-648

25 Bleske BE, Zineh I, Hwang HS, Welder GJ, Ghannam MM, Boluyt MO. Evaluation of hawthorn extract on immunomodulatory biomarkers in a pressure overload model of heart failure. Med Sci Monit 2007; 13: BR255-BR258

26 Mävers WH, Hensel $H$. Veränderungen der lokalen Myokarddurchblutung nach oraler Gabe eines Crataegusextraktes bei nichtnarkotisierten Hunden. Arzneimittelforschung 1974; 24: 783-785

27 Koch E, Chatterjee SS. Crataegus extract WS ${ }^{\circledR}-1442$ enhances coronary flow in the isolated rat heart by endothelial release of nitric oxide. Naunyn Schmiedeberg's Arch Pharmacol 2000; 361: R48

28 Brixius K, Willms S, Napp A, Tossios P, Ladage D, Bloch W, Mehlhorn U, Schwinger RH. Crataegus special extract WS 1442 induces an endothelium-dependent, NO-mediated vasorelaxation via eNOS-phosphorylation at serine 1177. Cardiovasc Drugs Ther 2006; 20: 177-184

29 Anselm E, Socorro VF, Dal-Ros S, Schott C, Bronner C, Schini-Kerth VB. Crataegus special extract WS 1442 causes endothelium-dependent relaxation via a redox-sensitive Src- and Akt-dependent activation of endothelial NO synthase but not via activation of estrogen receptors. J Cardiovasc Pharmacol 2009; 53: 253-260

30 Furst R, Zirrgiebel U, Totzke F, Zahler S, Vollmar AM, Koch E. The Crataegus extract $W S^{\circledR} 1442$ inhibits balloon catheter-induced intimal hyperplasia in the rat carotid artery by directly influencing PDGFR-beta. Atherosclerosis 2010; 211: 409-417

31 Koch E, Chatterjee SS. Crataegus extract WS ${ }^{\circledR} 1442$ compensates the decrease of cardiac output in endotoxemic rats. Eur Cytokine Network 2000; 11: 527

32 Fürst R, Bubik M, Bihari P, Juergenliemk G, Ammer H, Krombach F, Zahler $S$, Vollmar $A$. The hawthorn special extract WS ${ }^{\circledR} 1442$ protects against endothelial barrier dysfunction - elucidation of the underlying molecular mechanisms. Planta Med 2010; 76: 1191

33 Rajendran S, Deepalakshmi PD, Parasakthy K, Devaraj H, Devaraj SN. Effect of tincture of Crataegus on the LDL-receptor activity of hepatic plasma membrane of rats fed an atherogenic diet. Atherosclerosis 1996: 123: 235-241

34 Shanthi R, Parasakthy K, Deepalakshmi PD, Niranjali DS. Protective effect of tincture of Crataegus on oxidative stress in experimental atherosclerosis in rats. J Clin Biochem 1996; 20: 211-223

35 Zhang Z, Ho WKK, Huang Y, Chen ZY. Hypocholesterolemic activity of hawthorn fruit is mediated by regulation of cholesterol-7 $\alpha$-hydroxylase and acyl CoA: cholesterol acyltransferase. Food Res Int 2002; 35 : 885-891

36 Lin $Y$, Vermeer MA, Trautwein EA. Triterpenic acids present in hawthorn lower plasma cholesterol by inhibiting intestinal ACAT activity in hamsters. Evid Based Complement Alternat Med 2011: article ID 801272; doi: 10.1093/ecam/nep007

37 Koch E, Lanzendörfer-Goossens $H$, Weibezahn C. Crataegus extract WS ${ }^{\circledR}$ 1442 inhibits apolipoprotein B100 (ApoB) secretion and increases low-density lipoprotein receptor (LDL-R) transcription in human HepG2 cells. Z Phytother 2006; 27: S25-S26

38 Hecker-Niediek A. Untersuchungen zur Biogenese, Markierung und Pharmakokinetik der Procyanidine aus Crataegus-Spezies. Marburg: Marburg University; 1983

39 Liang $M, X u$ W, Zhang $W$, Zhang $C$, Liu R, Shen $Y$, Li H, Wang X, Pan $Q$ Chen $C$. Quantitative LC/MS/MS method and in vivo pharmacokinetic studies of vitexin rhamnoside, a bioactive constituent on cardiovascular system from hawthorn. Biomed Chromatogr 2007; 21: 422-429
40 Ma LY, Liu RH, Xu XD, Yu MQ, Zhang Q Liu HL. The pharmacokinetics of C-glycosyl flavones of hawthorn leaf flavonoids in rat after single dose oral administration. Phytomedicine 2010; 17: 640-645

41 Schlegelmilch $R$, Heywood R. Toxicity of Crataegus (hawthorn) extract (WS ${ }^{\circledR}$ 1442). J Am Coll Toxicol 1994; 13: 103-111

42 Yao M, Ritchie HE, Brown-Woodman PD. A reproductive screening test of hawthorn. J Ethnopharmacol 2008; 118: 127-132

43 Loew D. Phytotherapy in heart failure. Phytomedicine 1997; 4: 267271

44 Hawthorn leaf with flower. In: The Complete German Commission E Monographs. Boston: Integrative Medicine Communications; 1998: 142-144

45 Pittler MH, Guo R, Ernst E. Hawthorn extract for treating chronic heart failure. Cochrane Database Syst Rev 2008; 1: CD005312

46 Zick SM, Vautaw BM, Gillespie B, Aaronson KD. Hawthorn extract randomized blinded chronic heart failure (HERB CHF) trial. Eur J Heart Fail 2009; 11: 990-999

47 Tauchert M. Efficacy and safety of crataegus extract WS 1442 in comparison with placebo in patients with chronic stable New York Heart Association class-III heart failure. Am Heart J 2002; 143: 910-915

48 Eichstädt H, Störk T, Möckel M, Danne O, Funk P, Köhler S. Wirksamkeit und Verträglichkeit von Crataegus-Extrakt WS ${ }^{\circledR} 1442$ bei herzinsuffizienten Patienten mit eingeschränkter linksventrikulärer Funktion. Perfusion 2001; 14: 212-217

49 Zapfe Jr G. Clinical efficacy of crataegus extract WS 1442 in congestive heart failure NYHA class II. Phytomedicine 2001; 8: 262-266

50 Förster A, Förster K, Bühring $M$, Wolfstädter HD. Crataegus bei mäßig reduzierter linksventrikulärer Auswurffraktion. Münch Med Wschr 1994; 136: S21-S26

51 Schmidt U, Kuhn U, Ploch M, Hübner WD. Efficacy of hawthorn (Crataegus) preparation LI132 in 78 patients with chronic congestive heart failure defined as NYHA functional class II. Phytomedicine 1994; 1 : 17-24

52 Boedigheimer $K$, Chase $D$. Wirksamkeit von Weissdorn-Extrakt in der Dosierung $3 \mathrm{mal} 100 \mathrm{mg}$ täglich. Multizentrische Doppelblindstudie mit 85 herzinsuffizienten Patienten im Stadium NYHA II. Münch Med Wschr 1994; 136: 7-11

53 Weikl A, Assmus KD, Neukum-Schmidt A, Schmitz J, Zapfe G, Noh HS, Siegrist J. Crataegus-Spezialextrakt WS-1442. Objektiver Wirksamkeitsnachweis bei Patienten mit Herzinsuffizienz (NYHA II). Fortschr Med 1996; 114: 291-296

54 Leuchtgens H. Crataegus-Spezialextrakt WS-1442 bei Herzinsuffizienz NYHA II. Eine plazebokontrollierte randomisierte Doppelblindstudie. Fortschr Med 1993; 111: 352-354

55 Weikl A, Noh HS. Der Einfluss von Crataegus bei globaler Herzinsuffizienz. Herz Gefässe 1992; 12: 516-524

56 Eichstädt H, Bäder M, Danne O, Kaiser W, Stein U, Felix R. Crataegus-Extrakt hilft dem Patienten mit NYHA II-Herzinsuffizienz: Untersuchung der myokardialen und hämodynamischen Wirkung eines standardisierten Crataegus-Präparates mit Hilfe computergestützter Radionuklidventrikulographie. Therapiewoche 1989; 39: 3288-3296

57 Koller M, Lorenz W, Aubke W, Jensen A, Gerlach FM, Kühl J, Pfeil T, RegitzZagrosek V, Rusche H, Rychlik R. Weissdorn-Spezialextrakt in der Therapie früher Stadien der KHK-assoziierten Herzinsuffizienz. MMW Fortsch Med 2005; 147: 159-164

58 Holubarsch CJ, Colucci WS, Meinertz T, Gaus W, Tendera M. The efficacy and safety of Crataegus extract WS 1442 in patients with heart failure: the SPICE trial. Eur J Heart Fail 2008; 10: 1255-1263

59 Walker AF, Marakis G, Simpson E, Hope JL, Robinson PA, Hassanein M, Simpson HC. Hypotensive effects of hawthorn for patients with diabetes taking prescription drugs: a randomised controlled trial. $\mathrm{Br}$ J Gen Pract 2006; 56: 437-443

60 Daniele C, Mazzanti G, Pittler MH, Ernst E. Adverse-event profile of Crataegus spp.: a systematic review. Drug Saf 2006; 29: 523-535

61 Asher GN. Herbal products review. What do we really know? J Am Coll Cardiol 2010; 56: 903

62 Tankanow R, Tamer HR, Streetman DS, Smith SG, Welton JL, Annesley T, Aaronson $K D$, Bleske $B E$. Interaction study between digoxin and a preparation of hawthorn (Crataegus oxyacantha). J Clin Pharmacol 2003; 43: 637-642 